bioRxiv preprint doi: https://doi.org/10.1101/2021.04.20.440716; this version posted April 21, 2021. The copyright holder for this preprint (which was not certified by peer review) is the author/funder, who has granted bioRxiv a license to display the preprint in perpetuity. It is made available under aCC-BY 4.0 International license.

\title{
Recognition of Divergent Viral Substrates by the SARS-CoV-2 Main Protease
}

\author{
Elizabeth A. MacDonald, ${ }^{1}$ Gary Frey, ${ }^{2,3}$ Mark N. Namchuk, ${ }^{4}$ Stephen C. Harrison, ${ }^{1,4,5}$ Stephen M. Hinshaw, ${ }^{4, *, \dagger}$ and Ian W. \\ Windsor ${ }^{1,4,6, *}$ \\ *Correspondence: hinshaw@crystal.harvard.edu and windsor@crystal.harvard.edu \\ ${ }^{1}$ Laboratory of Molecular Medicine, Boston Children's Hospital, Boston, MA, USA \\ ${ }^{2}$ Department of Pediatrics, ${ }^{3}$ ICCB-Longwood Screening Facility, and ${ }^{4}$ Department of Biological Chemistry and Molecular \\ Pharmacology, Harvard Medical School, Boston, MA, USA \\ ${ }^{5}$ Howard Hughes Medical Institute, Boston, MA, USA \\ ${ }^{6}$ Ragon Institute of MGH, MIT, and Harvard, Cambridge, MA, USA
}

KEYWORDS: $S A R S-C o V-2, M^{\text {pro }}$, protease, virology

\begin{abstract}
The main protease $\left(\mathrm{M}^{\mathrm{pro}}\right)$ of severe acute respiratory syndrome coronavirus 2 (SARS-CoV-2), the cause of coronavirus disease (COVID-19), is an ideal target for pharmaceutical inhibition. It is required for infection, it cleaves the viral polyprotein at multiple sites, and it is conserved among coronaviruses and distinct from human proteases. We present crystal structures of SARSCoV-2 $\mathrm{M}^{\text {pro }}$ bound to two viral substrate peptides. The structures show how $\mathrm{M}^{\text {pro }}$ recognizes substrates and how the peptide sequence can dictate catalytic efficiency by influencing the position of the scissile bond. One peptide, constituting the junction between viral non-structural proteins 8 and 9 (nsp8/9), has P1' and P2' residues that are unique among SARS-CoV-2 cleavage sites but conserved among nsp8/9 junctions in coronaviruses. $\mathrm{M}^{\text {pro }}$ cleaves nsp8/9 inefficiently, and amino acid substitutions at $\mathrm{P}^{\prime}$ ' or $\mathrm{P}^{\prime}$ can enhance catalysis. Visualization of $\mathrm{M}^{\mathrm{pro}}$ with intact substrates provides new templates for antiviral drug design and suggests that the coronavirus lifecycle selects for finely tuned substrate-dependent catalytic parameters.
\end{abstract}

TEXT: Developing and stockpiling pan-coronavirus antiviral drugs for pandemic prevention has been a goal since the SARS outbreak of 2003., ${ }^{1,2}$ The coronavirus main protease (nsp5 or $\mathrm{M}^{\mathrm{pro}}$ ) is a conserved drug target and an important focus of these efforts. Hundreds of $\mathrm{M}^{\text {pro }}$ inhibitors have been reported. Most of these drugs occupy the active site cleft responsible for recognizing the $\mathrm{N}$-terminal half of substrate peptides, and many form covalent bonds to the active site cysteine of $\mathrm{M}^{\text {pro }}(\mathrm{Cys} 145) \cdot{ }^{3-7} \mathrm{~A}$

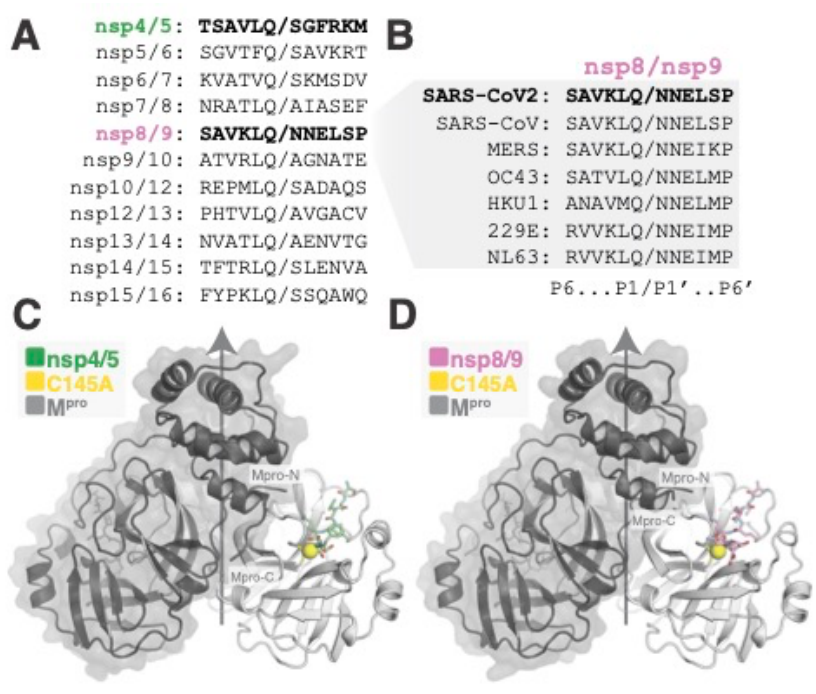

Figure 1. Viral substrates and structures of substrate-bound $\mathrm{M}^{\text {pro }}$. (A) Protein sequence alignment of the eleven SARS-CoV-2 $\mathrm{M}^{\text {pro }}$ cleavage sites required for maturation of SARS-CoV2. (B) Protein sequence alignment of nsp8/9 $\mathrm{M}^{\text {pro }}$ cleavage sites from representative coronaviruses. (C-D) Crystal structures showing nsp $4 / 5$ (C) or nsp8/9 (D) substrate engagement by $\mathrm{M}^{\text {pro }}$. Protease protomers are colored dark or light gray. A single peptide is colored for each, though peptide occupies all active sites in both determined structures. The vertical arrow marks the two-fold axis of the $\mathrm{M}^{\text {pro }}$ dimer. recent crystal structure of the nsp5/6 acyl-enzyme intermediate provides one template for chemical mimicry of this essential catalytic step. ${ }^{8}$ We provide evidence that contacts on both sides of the $\mathrm{M}^{\text {pro }}$ catalytic site can affect the rate of formation of the covalent complex, a characteristic that could be exploited by new protease inhibitors.

The nsp8/9 junction is a conserved $\mathrm{M}^{\mathrm{pro}}$ substrate (Figure 1AB). The nearly invariant Asn residues at $\mathrm{P}^{\prime}$ and $\mathrm{P} 2^{\prime}$ are unique within a given coronavirus polyprotein; all other cleavage sites have Gly, Ser, or Ala at P1', P2', or both sites. ${ }^{9}$ Cleavage of nsp8/9 is slow but required for replication of the closely-related Murine Hepatitis Virus. ${ }^{10}$ Indeed, a recently-determined cryoEM structure shows that the $\mathrm{N}$-terminus of nsp 9 contacts nsp12, a core component of the viral RNA polymerase. ${ }^{11}$ In this context, the nsp8/9 $\mathrm{P} 1^{\prime}$ to $\mathrm{P}^{\prime}$ residues contribute to a binding site for a nucleotide that is transferred to the amino terminus of the $\mathrm{P} 1$ ' residue. ${ }^{12}$ Therefore, the nsp $8 / 9$ junction has evolved to satisfy two evolutionary constraints required for viral replication: it must be cleaved in the $\mathrm{M}^{\mathrm{pro}}$ active site, and it must serve as a substrate in a nucleotide monophosphate transfer reaction catalyzed by the nsp 12 protein. We have used X-ray crystallography to study nsp $8 / 9$ and nsp $4 / 5$ recognition by $\mathrm{M}^{\text {pro }}$. The structures show unique features of the $\mathrm{M}^{\mathrm{pro}} \cdot \mathrm{nsp} 8 / 9$ complex constrained by natural selection and highlight the importance of $\mathrm{P}^{\prime}-\mathrm{P} 3^{\prime}$ residues in catalysis.

To study $\mathrm{M}^{\text {pro }}$ activity, we monitored cleavage of labeled substrate peptides in vitro and derived Michaelis-Menten parameters describing the reactions. $\mathrm{M}^{\text {pro }}$ cleavage of nsp $8 / 9$ is less efficient than cleavage of nsp4/5 (36-fold decrease in $k_{\mathrm{cat}} / K_{\mathrm{M}}$; Table 1). ${ }^{13}$ We also sought to understand the influence of the Asn residues at the $\mathrm{P}^{\prime}$ and $\mathrm{P} 2^{\prime}$ sites of the nsp8/9 substrate (Table 1). Alanine substitutions at either position approximately doubled the catalytic efficiency. The P1' Asn-to-Ala substitution lowered $K_{\mathrm{M}}$ and raised $k_{\text {cat, }}$, while the $\mathrm{P} 2^{\prime}$ substitution only raised 
bioRxiv preprint doi: https://doi.org/10.1101/2021.04.20.440716; this version posted April 21, 2021. The copyright holder for this preprint (which was not certified by peer review) is the author/funder, who has granted bioRxiv a license to display the preprint in perpetuity. It is made available under aCC-BY 4.0 International license.

Table 1. Catalytic efficiencies for $\mathrm{M}^{\text {pro }}$ substrates and analogs

\begin{tabular}{clcccc}
\hline Substrate & \multicolumn{1}{c}{ Sequence $^{\mathrm{a}}$} & $k_{\mathrm{cat}}\left(\mathrm{s}^{-1}\right)$ & $K_{\mathrm{M}}(\mu \mathrm{M})$ & $k_{\text {cat }} / K_{\mathrm{M}}\left(\mathrm{M}^{-1} \mathrm{~s}^{-1}\right)$ & Fold change $^{\mathrm{b}}$ \\
\hline nsp4/5 & TSAVLQ/SGFRKM & $0.52 \pm 0.07$ & $41 \pm 9$ & $1.3 \pm 0.3 \times 10^{4}$ & - \\
nsp8/9 & RVVKLQ/NNELMP & $0.013 \pm 0.001$ & $36 \pm 6$ & $3.6 \pm 0.7 \times 10^{2}$ & 1.0 \\
nsp8/9 N1'A & RVVKLQ/aNELMP & $0.022 \pm 0.001$ & $22 \pm 3$ & $1.0 \pm 0.1 \times 10^{3}$ & 2.9 \\
nsp8/9 N2'A & RVVKLQ/NaELMP & $0.034 \pm 0.002$ & $46 \pm 5$ & $7.5 \pm 0.8 \times 10^{2}$ \\
nsp8/9 N1'D & RVVKLQ/dNELMP & - & - & - & 2.1 \\
nsp8/9 N2'D & RVVKLQ/NdELMP & $0.0029 \pm 0.0001$ & $19 \pm 1$ & $1.6 \pm 1.2 \times 10^{2}$ \\
\hline
\end{tabular}

${ }^{\text {a}}$ Lys-DABCYL and Glu-EDANS and are appended to the N- and C-termini. Residues that differ from the wild-type sequence are lower case. ${ }^{\text {bFold change }}=\left(k_{\text {cat }} / K_{\mathrm{M}}\right)_{\text {nsp8/9 analog }} /\left(k_{\text {cat }} / K_{\mathrm{M}}\right)_{\mathrm{nsp} 8 / 9}$

$k_{\text {cat }}$ Installation of an isosteric Asp residue at the $\mathrm{P} 1^{\prime}$ position completely abrogated activity, while the analogous Asn-to-Asp substitution at $\mathrm{P} 2$ ' diminished but did not abrogate activity. We suspect that placing additional negative charge near the active site raises the energetic barrier to attaining the oxyanion transition states. ${ }^{14,15}$

Differences in $k_{\text {cat }}$ for the peptide substrates tested dominated the small changes in $K_{\mathrm{M}}$ and drove the observed changes in $k_{\text {cat }} / K_{\mathrm{M}}$. The P5-P1 residues were constant for nsp8/9 and its derivatives, ruling out acyl-enzyme hydrolysis as the step that determines $k_{\text {cat }}$. Therefore, either formation of the enzyme-substrate complex or conversion to the acyl-enzyme intermediate must limit $k_{\text {cat }}$ for the nsp8/9 substrate, and similar $K_{\mathrm{M}}$ values imply the latter is true. Unlabeled nsp8/9 did not inhibit cleavage of labeled nsp4/5 at concentrations up to $250 \mu \mathrm{M}$, while the control inhibitor MG-132 produced a $K_{\mathrm{i}}$ of $740 \mathrm{nM}$ (Figure S2). ${ }^{5}$ Its inability to interfere with nsp4/5 cleavage confirms that nsp8/9 is a poor $\mathrm{M}^{\text {pro }}$ substrate relative to $\mathrm{nsp} 4 / 5$. Similar competition among the 11 viral $\mathrm{M}^{\text {pro }}$ substrates occurs during virus replication.

To understand the structural basis for differential cleavage efficiency, we determined crystal structures of $\mathrm{M}^{\text {pro }}$ bound to the nsp4/5 and nsp8/9 substrates (Figure 1C-D). The active site Cys145Ala mutation trapped the intact substrates and enabled visualization of the $\mathrm{P}^{\prime}$ residues (Figure S3). A principal difference between the nsp4/5 and nsp8/9 substrates is the position of the scissile bond. The nsp8/9 P1 C $\alpha$ is translated $0.4 \AA$ along the $\mathrm{C}=\mathrm{O}$ axis relative to nsp4/5 (Figure 2). Nevertheless, 11 conserved hydrogen bonds occur between $\mathrm{M}^{\text {pro }}$ and each of the substrates (Figure 3, white dotted lines). Eight contacts between the peptide backbones of enzyme and substrate are shared among SARS-CoV nsp4/5, PEDV nsp4/5, ${ }^{16,17}$ and the two SARS-CoV-2 peptides reported here. M $^{\text {pro }}$ Gly143 and Ala145 mainchain amides form the oxyanion hole by donating a pair of hydrogen bonds to the scissile P1 carbonyl oxygen, which

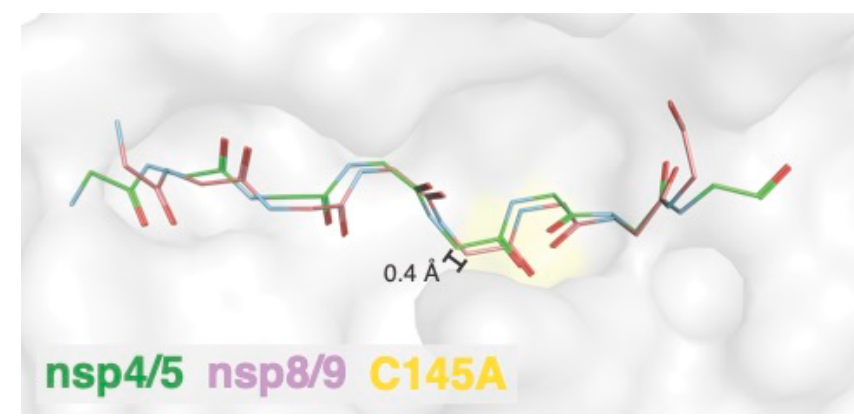

Figure 2. Backbone view showing shifted Mpro substrates. The catalytic site mutation Mpro Cys145Ala is yellow (surface). Distance between P1 C $\alpha$ for $\mathrm{nsp} 4 / 5$ (green) and nsp8/9 (pink) is given. stabilizes the developing negative charge during covalent catalysis. His163 and the mainchain carbonyl of Phe140 make hydrogen bonds with the invariant sidechain of the P1 Gln, and Asn 142 contacts the $\mathrm{P} 1 \mathrm{Gln}$ through a conserved water bridge. Neither SARS-CoV nor PEDV $\mathrm{M}^{\text {pro }} \cdot \mathrm{nsp}^{4 / 5}$ complexes show the hydrogen bonds observed with Asn142 in the SARS-CoV2 substrate complexes. ${ }^{16,17}$

Substrate interactions with the $\mathrm{M}^{\text {pro }}$ Asn142 and Gln189 sidechains distinguish nsp4/5 and nsp8/9 recognition (Figure 3, green and magenta dotted lines). $\mathrm{M}^{\text {pro }}$ Asn142 forms a hydrogen bond with the nsp4/5 $\mathrm{P}^{\prime}$ backbone carbonyl oxygen, and $\mathrm{M}^{\text {pro }}$ Gln189 forms a water bridge with the nsp4/5 P2 amide nitrogen. In contrast, $\mathrm{M}^{\text {pro }}$ Gln189 engages the nsp8/9 P3 and P1' side chains via an ordered water molecule. In addition to these contacts, the ordered waters found in the nsp8/9-bound structure could donate hydrogen bonds to the $\mathrm{P} 1{ }^{\prime}$ and $\mathrm{P} 2$ mainchain carbonyl oxygens. Finally, the nsp8/9 P3 Lys forms a hydrogen bond with the P2 carbonyl. This interaction and the ordered waters described above likely account for subtle bending of the nsp8/9 substrate P-fragment away from the active site cleft relative to the nsp4/5 peptide.

The peptide recognition described above produces the different catalytic efficiencies associated with cleavage of the nsp4/5 and nsp8/9 substrates. The near-invariant nsp8/9 P1' and P2' Asn side chains are bulkier than the $\mathrm{P}^{\prime}$ (Ser/Ala) and P2' (Gly/Ala) side chains of other $\mathrm{M}^{\text {pro }}$ substrates, though there is greater tolerance for $\mathrm{P} 2{ }^{\prime}$ diversity. ${ }^{18}$ The nsp8/9 P1' Asn reaches more deeply into the $\mathrm{S}^{\prime}$ subsite than the nsp4/5 P1' Ser and therefore likely restrains the $\mathrm{P}^{\prime}$ peptide to a greater degree. $\mathrm{M}^{\text {pro }}$ Asn 142 and Gly143 coordinate the nsp8/9 P2' residue through peptide backbone interactions, and similar interactions position the nsp4/5 P2' Gly (Figure 4A-B). Overall, the bulkier nsp8/9 Asn side chains in the $\mathrm{S} 1^{\prime}$ and $\mathrm{S} 2^{\prime}$ subsites shift nsp8/9 relative to nsp4/5 (Figure 2). The resulting alignment with the $\mathrm{M}^{\text {pro }}$ cysteine nucleophile differs from that of nsp $4 / 5$ and provides an explanation for reduced catalytic efficiency that is partially restored by alanine substitution. That the restoration is incomplete relative to nsp4/5 suggests that both $\mathrm{P}$ - and $\mathrm{P}^{\prime}$ - substrate fragments align the scissile bond.

Hydrophobic interactions dictate recognition of N-terminal substrate fragments ( $\mathrm{P}$ residues, excluding the invariant $\mathrm{P} 1$ Gln). $\mathrm{M}^{\text {pro }}$ Met49 and Met165 define the S4, S2, and S1' subsites (Figure 4). The nsp4/5 P3 Ala is smaller than the ns8/9 P3 Val, allowing the P4 Ala of nsp4/5 to sit more deeply in the S4 subsite. This produces a $1.0 \AA$ shift between the nsp $4 / 5$ and nsp8/9 P3 residues (measured from corresponding $\mathrm{C} \alpha$ atoms). A recent crystal structure shows that the intact nsp5/6 substrate is also shifted relative to nsp4/5 due to a bulky Phe at the P2 position (Figure $4 \mathrm{C}$ ). ${ }^{8}$ Indeed, $\mathrm{M}^{\text {pro }}$ cleavage is most efficient for peptides bearing P2 Leu and less efficient for those bearing 

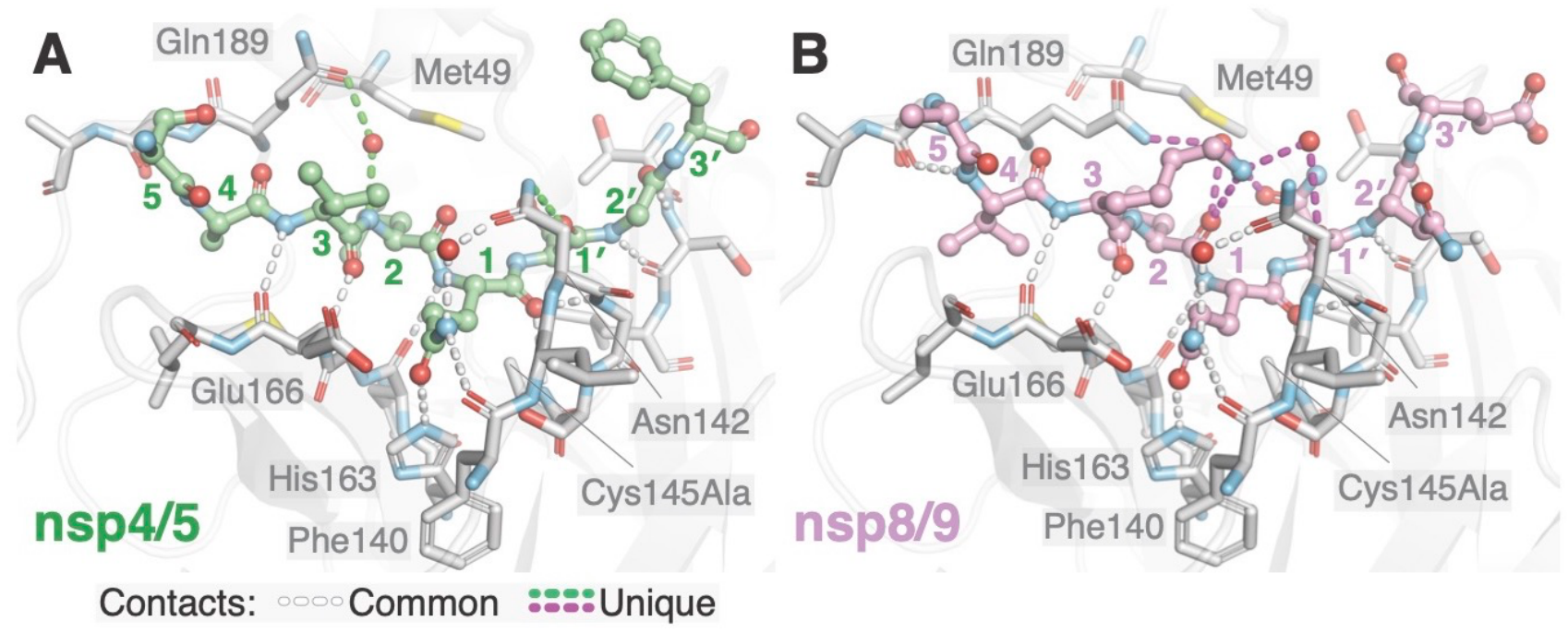

Figure 3. Differential recognition of nsp4/5 and nsp8/9 substrates by $\mathrm{M}^{\text {pro }}$. Identical views of nsp4/5 (A) and nsp8/9 (B) substrates in the $\mathrm{M}^{\text {pro }} \mathrm{Cys} 145 \mathrm{Ala}$ active site. Substrate peptide $\mathrm{P}$ and $\mathrm{P}^{\prime}$ residues are labeled with colored numbers. Key $\mathrm{M}^{\text {pro }}$ residues mentioned in the text are labeled. Conserved hydrogen bonds enabling $\mathrm{M}^{\mathrm{pro}}$ recognition of substrate mainchain and P1 Gln side chain atoms are shown as white dotted lines. The hydrogen bonds between $\mathrm{M}^{\text {pro }}$ and nsp $4 / 5$ (green) differ from those with nsp8/9 (magenta). $\mathrm{M}^{\text {pro }}$ Asn 142 and Gln 189 contact the nsp $4 / 5$ substrate through bound water molecules, while the same $\mathrm{M}^{\text {pro }}$ residues contact the nsp8/9 peptide at distinct sites through networked water molecules.

P2 Phe. ${ }^{19}$ Like nsp8/9, cleavage of SARS nsp5/6 depends more heavily on $\mathrm{P}^{\prime}$ recognition than does nsp4/5. ${ }^{20,21}$ The nsp8/9 P3 Lys might also limit catalysis. Water bridges connect its termi-

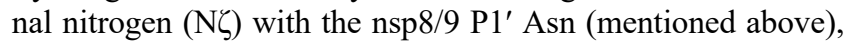
and the resulting conformation could slow peptide accommodation to the $\mathrm{M}^{\text {pro }}$ active site. Therefore, the diverse $\mathrm{M}^{\text {pro }}$-substrate interactions can fine-tune substrate geometry and position the scissile bond to adjust substrate-specific activity. ${ }^{22}$

The structures we have resolved show how $\mathrm{M}^{\text {pro }}$ active site plasticity and substrate evolution can tune catalysis. Slow cleavage of the nsp8/9 junction, which is observed among disparate coronaviruses, might be a selected trait required for coordinated assembly of the RNA replication machinery. ${ }^{9,13,23,24}$ Inability of the nsp8/9 substrate to inhibit nsp4/5 cleavage is likely important for maturation of the viral polyprotein. The need for the nsp8/9 junction to support both $\mathrm{M}^{\text {pro }}$ cleavage and nsp12 binding (and subsequent nucleotide monophosphate acceptance) accounts for the near-invariance of the P1-P2' residues. The sequence is therefore a compromise that satisfies the requirements of two unrelated catalytic mechanisms, and mimicry of the nsp8/9 junction presents a unique opportunity to chemically inhibit both $\mathrm{M}^{\text {pro }}$ and the viral polymerase.

The structures also present templates for new protease inhibitor scaffolds. In particular, that the nsp8/9 P3 sidechain can fold back to contact $\mathrm{P} 1^{\prime}$ suggests macrocyclic inhibitors could mimic this interaction. Similar strategies have been pursued for

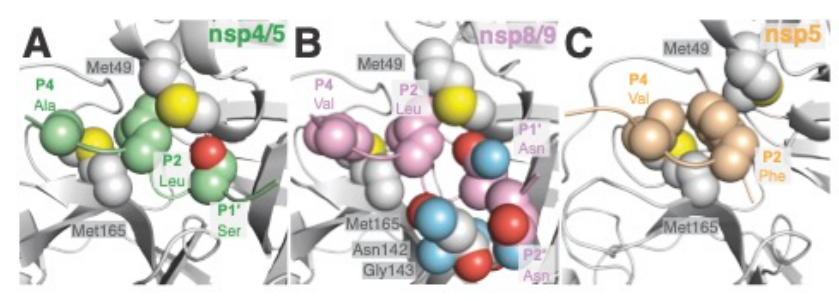

Figure 4. Steric effects that influence $\mathrm{M}^{\text {pro }}$ recognition and activity. Key atoms dictating the shape complementarity between $\mathrm{M}^{\text {pro }}$ subsites and corresponding side chains from: (A) nsp4/5, (B) nsp8/9, and (C) nsp5 (acylenzyme intermediate; PDB 7KHP).
Hepatitis C NS3, HIV-1, and Rhinovirus 3C proteases. ${ }^{25-27} \mathrm{Ki}-$ netic analyses of nsp8/9 and its variants suggests that inhibitor $\mathrm{P} 1^{\prime}$ and $\mathrm{P} 2^{\prime}$ site contacts could influence formation of covalent inhibitor-enzyme adducts. $\alpha$-ketoamide warheads, which have not been exhaustively explored as ligands for $\mathrm{M}^{\text {pro }} \mathrm{Cys} 145$, are good candidates for this objective.

\section{ASSOCIATED CONTENT}

\section{Supporting Information}

Supporting Information document contains methods, inhibition experiments, and crystallographic information. Crystallographic data has been deposited at the PDB with associated codes 7MGR $\left(\mathrm{M}^{\mathrm{pro}} \cdot \mathrm{nsp} 8 / 9\right)$ and 7MGS (M $\left.{ }^{\mathrm{pro}} \cdot \mathrm{nsp} 4 / 5\right)$.

\section{AUTHOR INFORMATION}

\section{Corresponding Author}

* Stephen M. Hinshaw - hinshaw@crystal.harvard.edu and Ian W. Windsor - windsor@crystal.harvard.edu

\section{Present Address}

$\uparrow$ Stanford Cancer Institute, Stanford University School of Medicine, Stanford, CA, USA

\section{Author Contributions}

The manuscript was written through contributions of all authors. All authors have given approval to the final version of the manuscript.

\section{Funding Sources}

We acknowledge funding support from the Massachusetts Consortium for Pathogen Readiness (M.N.N.), the Howard Hughes Medical Institute (S.C.H.), and the Nancy Lurie Marks Family Foundation (S.C.H.). S.M.H. is an HHMI Fellow of the Helen Hay Whitney Foundation. NE-CAT is supported by NIH grant P30 GM 124165 . 
bioRxiv preprint doi: https://doi.org/10.1101/2021.04.20.440716; this version posted April 21, 2021. The copyright holder for this preprint (which was not certified by peer review) is the author/funder, who has granted bioRxiv a license to display the preprint in perpetuity. It is made available under aCC-BY 4.0 International license.

\section{ACKNOWLEDGMENTS}

Enzyme assays were performed at the Institute for Chemistry and Chemical Biology (ICCB-Longwood) at Harvard Medical School. We thank Linlin Zhang (Hilgenfeld Laboratory, University of Lübeck) for providing the codon-optimized Mpro expression plasmid. X-ray diffraction data were collected at the Advanced Photon Source (APS) on NE-CAT beamline 24-IDC.

\section{REFERENCES}

1. Anand, K.; Ziebuhr, J.; Wadhwani, P.; Mesters, J. R.; Hilgenfeld, R., Coronavirus main proteinase (3CLpro) structure: basis for design of anti-SARS drugs. Science 2003, 300 (5626), 1763-7.

2. Hilgenfeld, R., From SARS to MERS:

crystallographic studies on coronaviral proteases enable antiviral drug design. FEBS J 2014, 281 (18), 4085-96. 3. Zhang, L.; Lin, D.; Sun, X.; Curth, U.; Drosten, C.; Sauerhering, L.; Becker, S.; Rox, K.; Hilgenfeld, R., Crystal structure of SARS-CoV-2 main protease provides a basis for design of improved alpha-ketoamide inhibitors. Science 2020, 368 (6489), 409-412.

4. $\quad$ Lockbaum, G. J.; Reyes, A. C.; Lee, J. M.; Tilvawala, R.; Nalivaika, E. A.; Ali, A.; Kurt Yilmaz, N.; Thompson, P. R.; Schiffer, C. A., Crystal Structure of SARSCoV-2 Main Protease in Complex with the Non-Covalent Inhibitor ML188. Viruses 2021, 13 (2).

5. Ma, C.; Sacco, M. D.; Hurst, B.; Townsend, J. A.; Hu, Y.; Szeto, T.; Zhang, X.; Tarbet, B.; Marty, M. T.; Chen, Y.; Wang, J., Boceprevir, GC-376, and calpain inhibitors II, XII inhibit SARS-CoV-2 viral replication by targeting the viral main protease. Cell Res 2020, 30 (8), 678692.

6. Rathnayake, A. D.; Zheng, J.; Kim, Y.; Perera, K. D.; Mackin, S.; Meyerholz, D. K.; Kashipathy, M. M.; Battaile, K. P.; Lovell, S.; Perlman, S.; Groutas, W. C.; Chang, K. O., 3C-like protease inhibitors block coronavirus replication in vitro and improve survival in MERS-CoVinfected mice. Sci Transl Med 2020, 12 (557).

7. Dai, W.; Zhang, B.; Jiang, X. M.; Su, H.; Li, J.; Zhao, Y.; Xie, X.; Jin, Z.; Peng, J.; Liu, F.; Li, C.; Li, Y.; Bai, F.; Wang, H.; Cheng, X.; Cen, X.; Hu, S.; Yang, X.; Wang, J.; Liu, X.; Xiao, G.; Jiang, H.; Rao, Z.; Zhang, L. K.; Xu, Y.; Yang, H.; Liu, H., Structure-based design of antiviral drug candidates targeting the SARS-CoV-2 main protease. Science 2020, 368 (6497), 1331-1335.

8. Lee, J.; Worrall, L. J.; Vuckovic, M.; Rosell, F. I.; Gentile, F.; Ton, A. T.; Caveney, N. A.; Ban, F.; Cherkasov, A.; Paetzel, M.; Strynadka, N. C. J., Crystallographic structure of wild-type SARS-CoV-2 main protease acylenzyme intermediate with physiological C-terminal autoprocessing site. Nat Commun 2020, 11 (1), 5877.

9. Hegyi, A.; Ziebuhr, J., Conservation of substrate specificities among coronavirus main proteases. J Gen Virol 2002, 83 (Pt 3), 595-599.

10. Deming, D. J.; Graham, R. L.; Denison, M. R.; Baric, R. S., Processing of open reading frame 1a replicase proteins nsp7 to nsp10 in murine hepatitis virus strain A59 replication. J Virol 2007, 81 (19), 10280-91.

11. Yan, L.; Ge, J.; Zheng, L.; Zhang, Y.; Gao, Y.; Wang, T.; Huang, Y.; Yang, Y.; Gao, S.; Li, M.; Liu, Z.; Wang, H.; Li, Y.; Chen, Y.; Guddat, L. W.; Wang, Q.; Rao, Z.; Lou, Z., Cryo-EM Structure of an Extended SARS-CoV-2 Replication and Transcription Complex Reveals an

MacDonald et al.
Intermediate State in Cap Synthesis. Cell 2021, 184 (1), 184$193 \mathrm{e} 10$.

12. Slanina, H.; Madhugiri, R.; Bylapudi, G.; Schultheiss, K.; Karl, N.; Gulyaeva, A.; Gorbalenya, A. E.; Linne, U.; Ziebuhr, J., Coronavirus replication-transcription complex: Vital and selective NMPylation of a conserved site in nsp9 by the NiRAN-RdRp subunit. Proc Natl Acad Sci US A 2021, 118 (6).

13. Krichel, B.; Falke, S.; Hilgenfeld, R.; Redecke, L.; Uetrecht, C., Processing of the SARS-CoV ppla/ab nsp7-10 region. Biochem J 2020, 477 (5), 1009-1019.

14. Robertus, J. D.; Kraut, J.; Alden, R. A.; Birktoft, J. J., Subtilisin; a stereochemical mechanism involving transition-state stabilization. Biochemistry 1972, 11 (23), 4293-303.

15. Simon, L.; Goodman, J. M., Enzyme catalysis by hydrogen bonds: the balance between transition state binding and substrate binding in oxyanion holes. J Org Chem 2010, 75 (6), 1831-40.

16. Xue, X.; Yu, H.; Yang, H.; Xue, F.; Wu, Z.; Shen, W.; Li, J.; Zhou, Z.; Ding, Y.; Zhao, Q.; Zhang, X. C.; Liao, M.; Bartlam, M.; Rao, Z., Structures of two coronavirus main proteases: implications for substrate binding and antiviral drug design. J Virol 2008, 82 (5), 2515-27.

17. Ye, G.; Deng, F.; Shen, Z.; Luo, R.; Zhao, L.; Xiao, S.; Fu, Z. F.; Peng, G., Structural basis for the dimerization and substrate recognition specificity of porcine epidemic diarrhea virus 3C-like protease. Virology 2016, 494, 225-35.

18. Koudelka, T.; Boger, J.; Henkel, A.; Schonherr, R.; Krantz, S.; Fuchs, S.; Rodriguez, E.; Redecke, L.; Tholey, A., N-Terminomics for the Identification of In Vitro Substrates and Cleavage Site Specificity of the SARS-CoV-2 Main Protease. Proteomics 2021, 21 (2), e2000246.

19. Rut, W.; Groborz, K.; Zhang, L.; Sun, X.; Zmudzinski, M.; Pawlik, B.; Wang, X.; Jochmans, D.; Neyts, J.; Mlynarski, W.; Hilgenfeld, R.; Drag, M., SARSCoV-2 M(pro) inhibitors and activity-based probes for patientsample imaging. Nat Chem Biol 2021, 17 (2), 222-228.

20. Muramatsu, T.; Takemoto, C.; Kim, Y. T.; Wang, H.; Nishii, W.; Terada, T.; Shirouzu, M.; Yokoyama, S., SARS-CoV 3CL protease cleaves its C-terminal autoprocessing site by novel subsite cooperativity. Proc Natl Acad Sci U S A 2016, 113 (46), 12997-13002.

21. Xue, X.; Yang, H.; Shen, W.; Zhao, Q.; Li, J.; Yang, K.; Chen, C.; Jin, Y.; Bartlam, M.; Rao, Z., Production of authentic SARS-CoV M(pro) with enhanced activity: application as a novel tag-cleavage endopeptidase for protein overproduction. J Mol Biol 2007, 366 (3), 965-75. 22. Kneller, D. W.; Phillips, G.; O'Neill, H. M.; Jedrzejczak, R.; Stols, L.; Langan, P.; Joachimiak, A.; Coates, L.; Kovalevsky, A., Structural plasticity of SARSCoV-2 3CL M(pro) active site cavity revealed by room temperature X-ray crystallography. Nat Commun 2020, 11 (1), 3202.

23. Gildenhuys, S., Expanding our understanding of the role polyprotein conformation plays in the coronavirus life cycle. Biochem J 2020, 477 (8), 1479-1482.

24. Snijder, E. J.; Decroly, E.; Ziebuhr, J., The Nonstructural Proteins Directing Coronavirus RNA Synthesis and Processing. Adv Virus Res 2016, 96, 59-126.

25. Li, X.; Zhang, Y. K.; Liu, Y.; Ding, C. Z.; Zhou, Y.; Li, Q.; Plattner, J. J.; Baker, S. J.; Zhang, S.; 
bioRxiv preprint doi: https://doi.org/10.1101/2021.04.20.440716; this version posted April 21, 2021. The copyright holder for this preprint (which

was not certified by peer review) is the author/funder, who has granted bioRxiv a license to display the preprint in perpetuity. It is made available under aCC-BY 4.0 International license.

Kazmierski, W. M.; Wright, L. L.; Smith, G. K.; Grimes, R. $\quad$ ray studies, and biological evaluation of novel macrocyclic M.; Crosby, R. M.; Creech, K. L.; Carballo, L. H.; Slater, M. J.; Jarvest, R. L.; Thommes, P.; Hubbard, J. A.;

HIV-1 protease inhibitors involving the P1'-P2' ligands. Convery, M. A.; Nassau, P. M.; McDowell, W.; Skarzynski, T. J.; Qian, X.; Fan, D.; Liao, L.; Ni, Z. J.; Pennicott, L. E.; Zou, W.; Wright, J., Novel macrocyclic HCV NS3 protease inhibitors derived from alpha-amino cyclic boronates. Bioorg Med Chem Lett 2010, 20 (19), 5695-700.

26. Ghosh, A. K.; Sean Fyvie, W.; Brindisi, M.; Steffey, M.; Agniswamy, J.; Wang, Y. F.; Aoki, M.; Bioorg Med Chem Lett 2017, 27 (21), 4925-4931.

27. Namoto, K.; Sirockin, F.; Sellner, H.; Wiesmann, C.; Villard, F.; Moreau, R. J.; Valeur, E.; Paulding, S. C.; Schleeger, S.; Schipp, K.; Loup, J.; Andrews, L.; Swale, R.; Robinson, M.; Farady, C. J., Structure-based design and synthesis of macrocyclic human rhinovirus $3 \mathrm{C}$ protease inhibitors. Bioorg Med Chem Lett 2018, 28 (5), 906-909.

Amano, M.; Weber, I. T.; Mitsuya, H., Design, synthesis, X- 